\title{
Redes de ciudades pequeñas en el territorio peruano. Un análisis tipológico a partir del caso de la región La Libertad
}

Small Cities Networks in the Peruvian Territory. A Typological Analysis from the Case of La Libertad Region

Redes de cidades pequenas no território peruano. Uma análise tipológica a partir do caso da região La Libertad

Marta Vilela Malpartida*

Pablo Vega Centeno**

Recibido: 27 de septiembre de 2019

Aprobado: 3 de mayo de 2020

https://doi.org/10.12804/revistas.urosario.edu.co/territorios/a.8287

Para citar este artículo:

Vilela Malpartida, M., \& Vega Centeno, P. (2020). Redes de ciudades pequeñas en el territorio peruano. Un análisis tipológico a partir del caso de la región La Libertad. Territorios, (43-Especial), pp. 1-25. https:// doi.org/10.12804/revistas.urosario.edu.co/territorios/a.8287

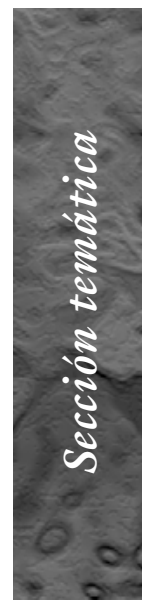

* Pontificia Universidad Católica del Perú. Correo electrónico:mrvilela@pucp.edu.pe ORCID: https:// orcid.org/0000-00016822-8210

** Pontificia Universidad Católica del Perú. Correo electrónico:pvega@pucp. edu.pe ORCID: http:// orcid.org/0000-00020880-3196 
Palabras clave

Ciudades intermedias; territorio; redes

territoriales; tipologías de redes; contracción espaciotemporal.

Keywords

Intermediates cities; territory; territorial networks; territorial unit; space-time contraction.

Palavras-chave

Cidades intermediárias; território; redes territoriais; tipologias de redes; contração espaço temporal.

\section{tersitarias 43-Especial}

\section{RESUMEN}

En países como Perú, la actividad económica a escala global ocurre en territorios diversos de población dispersa. No se han podido evaluar de manera eficiente sus efectos debido a que hemos estudiado poco las redes urbanas cuando hay aglomeraciones pequeñas y dispersas en el territorio. Por ello, el interés se centró en realizar un estudio sobre cómo se distribuyen y relacionan las diferentes localidades que ocupan territorios de geografía diversa y accidentada. La investigación propone la elaboración de tipologías de redes en unidades territoriales como estrategia de análisis para identificar el rol de intermediación de las ciudades pequeñas. Para el análisis tipológico se tomaron como indicadores la densidad de ocupación, la distribución de servicios públicos, los usos del suelo y la contracción espaciotemporal. Como estudio de caso se eligieron tres unidades territoriales en la región de La Libertad, en el norte del Perú. Los resultados permitieron identificar tipologías de redes de ciudades pequeñas que muestran marcadas diferencias en la ocupación del territorio.

\section{Abstract}

In countries like Peru, global economic activity occurs in diverse territories of scattered population. We have not efficiently assessed their effects because we do not have studied urban networks when there are small and dispersed agglomerations in the territory. Therefore, the focus was on conducting a study on how the different localities occupying territories of diverse and hilly geography distribute and relate. The research proposes the development of network typologies in territorial units as an analysis strategy to identify the role of intermediation in small towns. Occupancy density, utility distribution, land uses, and temporary space contraction were taken as indicators for the typological analysis. Three territorial units were chosen as a case study in La Libertad, a northern Peru region. The results made it possible to identify types of small-town networks that show marked differences in the occupation of the territory.

\section{Resumo}

Em Países como o Peru, a atividade econômica à escala global ocorre em territórios diversos de população dispersa, mas não podemos avaliar de maneira eficiente seus efeitos na medida que temos estudado pouco as redes urbanas quando há aglomerações pequenas e dispersas no território. Por isso, o interesse se centrou em realizar um estudo sobre a forma em que se distribuem e relacionam as diferentes localidades que ocupam territórios de geografia diversa e acidentada. A pesquisa propõe a elaboração de tipologia de redes em unidades territoriais como estratégia de análise para identificar o papel de intermediação de cidades pequenas. Para a análise tipológica se tomaram como indicadores a densidade de ocupação, a distribuição de serviços públicos, os usos de solo e a contração espaço-temporal. Como estudo de caso se elegeram três unidades territoriais na região de La Libertad, no norte do Peru. Os resultados permitiram identificar tipologias de redes de cidades pequenas que mostram marcadas diferenças na ocupação do território. 


\section{Introducción}

Históricamente el Perú ha sido un país cuya economía ha dependido de sus materias primas desde el oro y la plata en el siglo XVI, hasta el cobre, el zinc y el oro en el siglo XXI. Después de la década de 1980, donde la convulsión política y la crisis económica retrajeron la presencia de capitales transnacionales, las últimas tres décadas han significado el retorno de grandes capitales, atraídos por una política económica estable, orientada a facilitar las inversiones privadas de gran escala. Este gran capital ingresa con nuevas estructuras de operación, que priorizan la conectividad del sitio de explotación con las grandes ciudades, en las que ejercieron control territorial, sobre todo en los entornos en los que desarrollaron sus actividades extractivas o de transformación entre finales del siglo XIX y la mayor parte del siglo Xx. En el marco de las actuales políticas de atracción del gran capital, la inversión vial desarrollada en estas décadas ha sido difundida como uno de los grandes indicadores de progreso del país. Sin embargo, poco sabemos de los efectos que este tipo de articulación del territorio nacional genera sobre las redes económicas locales preexistentes.

Esta falta de comprensión se debe, en buena parte, a la escasez de trabajos de investigación sobre las dinámicas urbanas de las ciudades más pequeñas. Como señala un estudio reciente sobre la cuestión urbana en el Perú, las investigaciones se han concentrado mayoritariamente en Lima (Calderón \& Vega Centeno, 2016). Es necesario entonces enriquecer nuestro conocimiento de los fenómenos urbanos de menor escala que se hayan dispersos en el territorio.

Con base en este interés, se ha escogido como caso de estudio La Libertad, una de las regiones peruanas con mayor crecimiento económico, principalmente por las grandes inversiones en minería y agroindustria durante las últimas dos décadas. Nuestro objetivo es identificar cómo se construyen actualmente las redes urbanas en las que no está presente una gran ciudad, y de qué manera estas articulan un territorio a escala local. La hipótesis de trabajo es que estas redes operan gracias al rol de intermediación de las ciudades pequeñas, que permiten la articulación de unidades territoriales caracterizadas por medios físicos accidentados, diversos y dispersos.

Se propone como aproximación metodológica elaborar una tipología de redes, consolidando cada una de ellas como una unidad territorial. Para esta tipología se utilizaron dos grupos de indicadores: la densidad de ocupación y usos del territorio, por una parte, $y$, por otra, la contracción espaciotemporal a partir de la distribución de servicios de educación y salud en la forma que adquiere la red vial existente, atendiendo los accidentes geográficos del territorio que debe atravesar.

Con los resultados obtenidos se espera contribuir a la discusión en torno a las territorios 43-Especial 
formas de integración que establecen los procesos locales con relación al tipo de territorio que ocupan y los diferentes roles que adquieren las ciudades pequeñas.

\section{El territorio y las ciudades intermedias}

La explosión demográfica ocurrida en América Latina, a mediados del siglo XX, desembocó en procesos urbanos fuertemente centralizados, muchos de ellos en torno a una gran ciudad, fenómeno que fue definido por Castells (1973) como un "sistema urbano macrocefálico". Esto llevó a que el foco de atención de los estudios urbanos en América Latina se centrara casi exclusivamente en lo que estaba ocurriendo en las grandes ciudades. En el Perú, en particular, los estudios sobre Lima fueron casi excluyentes.

Si bien en casos como el del Perú la metrópoli de Lima representa actualmente cerca de la tercera parte de la población nacional, no se debe soslayar que, de acuerdo con el reciente Censo INEI de 2017 , el $27,85 \%$ de la población habita en aglomeraciones urbanas de 500 a 50000 habitantes. Estas ciudades, de tamaño pequeño, han merecido poca atención para la investigación urbana, a pesar de estar dispersas a lo largo y ancho del complejo territorio peruano. ¿Qué papel juegan estas aglomeraciones en el actual sistema urbano nacional? Es indispensable entender el rol que desempeñan como articuladoras entre poblaciones rurales y aglomeraciones urbanas de mayor tamaño, pues será la única forma de poder identificar los efectos que nuevas inversiones viales pueden generar sobre los territorios que ocupan. Desde esta perspectiva, consideramos pertinente aproximarnos a estas aglomeraciones entendiéndolas como ciudades intermedias.

El estudio de las ciudades intermedias supone un amplio debate sobre cómo definirlas. Las instituciones públicas multilaterales o nacionales tienden a clasificarlas según el tamaño demográfico, pero muchos estudios coinciden en la necesidad de definirlas a partir del rol que cumplen en el territorio. Así, tenemos autores que subrayan su carácter de intermediación (Carrión, 2013) o vertebración de sistemas en una red que involucra tanto a centros urbanos de escala local, como espacios rurales (Schejtman, 2013; Llop et al., 2019), incidiendo en algún indicador particular como su rol administrativo, función urbana o su morfología (Demazière, 2017); los flujos de distribución de bienes y servicios (Bellet \& Llop, 2004), o en su responsabilidad territorial (Schor \& de Oliveira, 2011)), aunque también hay trabajos que se interesan más por el grado de articulación global de estos centros urbanos, que por su rol en la escala local (Montoya \& Duque, 2017; Pulido, 2004).

El papel que adquieren las ciudades intermedias es susceptible de ser mejor entendido, partiendo de un enfoque territorial, en el cual el territorio se entiende como la manifestación del vínculo entre un 
sistema social — que incluye subsistemas económicos y culturales - y un sistema natural en un espacio determinado (Magnaghi, 2011). Esta relación es definida como un proceso que incluye los tipos de ocupación y transformación de recursos con base en las relaciones sociales de poder disímiles, que determinan la construcción de una historia y cultura comunes (Schneider \& Peyré, 2006). De esta forma, se hace necesario estudiar una ciudad intermedia en el marco de la identificación de unidades territoriales.

Una unidad territorial consiste en la ocupación humana de una superficie, que no debe asociarse necesariamente a una estructura de tipo zonal, sino que puede ser reticular, sin ser excluyentes una de otra (Haesbert 2013, p. 22-23). Desde esta perspectiva, el estudio de las redes de ciudades identifica en qué medida se consolidan entidades territoriales dinámicas, como señalan Bretagnolle et al. (2010), que se soportan en la complementariedad, la reciprocidad y la asociatividad, por lo que debe prestarse especial atención a las formas de gobernabilidad (Vilela, 2009). Por ello, el enfoque territorial supone también vincular los procesos que ocurren en un espacio físico y humano con la discusión de políticas públicas que puedan orientar la intervención del Estado a diversas escalas (Schneider \& Peyré, 2006).

Este enfoque territorial supone evidenciar las relaciones antes que las condiciones estáticas y estructurales. Por ello, estudiar las relaciones entre ciudades es relevante y supone espacializar las políticas públicas, cambiando la lógica vigente - políticas definidas y decididas desde el poder central del Estado- por una aproximación más local, articulada al territorio como señalan Gallicchio (2010) y Enríquez (2019).

Desde esta perspectiva, en el caso del Perú, Bielza (2012) indica que es necesario priorizar las políticas de desarrollo regional considerando como reto la reducción de la pobreza, basándose en el sistema de ciudades y el policentrismo (p. 101). Por su parte, Hall y Pain (2006) señalan que las políticas deben centrarse en las relaciones funcionales entre ciudades que además incentiven relaciones complementarias y no de competencia. Así mismo, resaltan que las relaciones funcionales son importantes para atender asuntos que no resuelve el mercado como la inversión en infraestructura y servicios públicos a gran escala (p. 121).

En el marco de un enfoque territorial, identificar las redes de ciudades a partir de tipologías constituye una aproximación sugerente pues permite discutir, por ejemplo, en qué medida estas se derivan de una ocupación donde un solo centro organiza la ocupación y la retícula de ciudades. En el caso de una ocupación de fuerte tendencia centralista, se genera una acumulación muy alta de servicios tanto para la producción agrícola, como para la actividad urbana en el núcleo principal, dejando a las otras aglomeraciones en una relación de dependencia del centro. En cambio, en una ocupación urbana territorios 43-Especial 
${ }^{1}$ Por lo general, una red se compone de centros $y$ vinculos. En este caso se incorpora también la superficie (Vilela, 2017).

${ }^{2}$ La densidad es un concepto ligado a los recursos $y$ condiciones de habitabilidad de la superficie que se ocupa. Esta relación de población sobre un área determinada y la de su potencialidad o calidad para el desarrollo de la vida bumana es la que nos interesa.

${ }^{3}$ Estos dos aspectos son considerados como estratégicos para la reducción de la pobreza y de las desigualdades en territorios de paises en vias de desarrollo (Oxfam, 2014).

${ }^{4}$ La contracción espaciotemporal se refiere a las restricciones que pueda tener el movimiento -la acción que permite superar la separación de los aspectos espaciales $y$ temporales- (Bernard, 2015). Variables como la distancia o la velocidad son decisivas en los tipos de contracción, pero en el caso de territorios como el andino, la pendiente del terreno también se convierte en un factor determinante. La perspectiva de Bretagnolle et al.

\section{territarios}

\section{3-Especial}

reticular no centralizada, la diferencia de cada centro urbano es la que va a generar la dinámica. Por ejemplo, una ciudad concentra servicios urbanos, otra actividad comercial y otros centros actividades de carácter administrativo. Este último tipo de ocupación tiende a generar intercambios que favorecen las relaciones de complementariedad entre ellas, lo que permitirá que los centros poblados, dentro de esta red, conformen una unidad territorial relativamente autónoma de grandes ciudades, pero que a la vez les permite establecer relaciones con urbes de mayor tamaño e importancia.

En un sentido más amplio, Máttar y Riffo (2013) destacan la necesidad de políticas públicas explícitas para reducir las grandes desigualdades socioespaciales en América Latina (p. 44). En ese sentido, la planificación y gestión, entendidas como procesos políticos e instrumentos orientados hacia el desarrollo integral y concertado, son necesarias para el desarrollo equilibrado del territorio.

También es necesario enfocarse en las potencialidades económicas de cada ciudad bajo una visión integradora, además de la coordinación entre los distintos niveles y sectores del gobierno (Hall \& Pain, 2006, p. 121). De este modo, el ordenamiento territorial de escala local, como estrategia de desarrollo, debe plantearse la necesidad de articular las aproximaciones sociales y económicas con las espaciales, para generar sinergias en pro de un desarrollo local eficiente, sostenible y con inclusión social.
Según Schejtman (2013), un enfoque territorial debe aportar a reducir la pobreza y las inequidades sociales.

Es desde esta perspectiva que interesa estudiar la configuración de redes territoriales a nivel local. Estas se estarían redefiniendo por la presencia de grandes inversiones privadas a escala global o suprarregional en sus unidades territoriales. Por lo tanto, se busca comprender cuál es el rol de intermediación que cumplen las ciudades pequeñas. Interesa observar, entender e interpretar la ocupación espacial en la unidad territorial, ya que su fortalecimiento y eficiencia se erige como el soporte para el desarrollo local.

\section{Metodología de identificación de tipologías de redes de ciudades menores}

La identificación de una tipología de redes de ciudades menores es posible a partir del análisis de la forma espacial que estas adquieren, considerando la superficie que abarcan, ${ }^{1}$ las condiciones del medio físico - pendiente y proximidad a recursos - y las relaciones espaciales que permiten. Para ello, se utilizaron dos tipos de variables. Por una parte, la densidad territorial, ${ }^{2}$ relativa al crecimiento poblacional en el espacio de actuación de la red, y el crecimiento del continuo urbano, en relación con la proximidad a los recursos existentes y servicios públicos como los de educación y salud. ${ }^{3}$ Por otra parte, la contracción espaciotemporal, ${ }^{4}$ relativa a la 
accesibilidad territorial a escala local que puede ejercerse desde centros poblados menores a mayores por los servicios de educación y salud, según los tipos de la conectividad existente, la calidad de las vías, las características del territorio y las rutas de servicio de transporte.

La densidad territorial expresa la relación entre tamaño poblacional y acceso a recursos por proximidad, mientras que la contracción espacio temporal da cuenta de los niveles de conectividad y accesibilidad local. La contracción espaciotemporal se basa en que son los movimientos los que construyen el espacio y el tiempo en relación con un objeto (Bernard, 2015).

Para completar la información en torno a ambas variables se utilizaron tanto bases de información censal, como información estadística de los sectores de educación, salud, transporte y comunicaciones del Centro Regional de Planeamiento Estratégico del Gobierno Regional de La Libertad (CERPLAN-GRLL) al año 2014. Asimismo, se utilizaron imágenes Landsat y estadísticas del Ministerio del Ambiente y del Instituto Geológico y Metalúrgico (Ingemet); por último, se levantó información de destinos y flujos de pasajeros en los paraderos de transporte público de las ciudades estudiadas. Esta información fue sistematizada en representaciones espaciales. Mediante mesas de trabajo con líderes locales y autoridades, se analizó la valoración de los cambios y la conectividad en la vida cotidiana de los habitantes.

\section{Los casos de unidades territoriales en la región La Libertad}

Las unidades territoriales conformadas sin un gran centro urbano se han visto expuestas a cambios importantes durante las primeras dos décadas del siglo XXI como consecuencia del desarrollo de actividades como la minería y la agroindustria, con estructuras empresariales de escala suprarregional e incluso global. Este es el caso de la región La Libertad, donde importantes inversiones mineras y agroindustriales están generando impacto no solo por su actividad, sino por las inversiones viales que el Estado viene llevando a cabo para favorecerlas. Por ello, el estudio de las redes urbanas de ciudades pequeñas resulta pertinente para evaluar la magnitud de estos cambios. Para el presente estudio, nos hemos concentrado en lo que ocurre en torno a cuatro ciudades pequeñas que cumplen el rol de capital de provincia en territorios compuestos por numerosos centros poblados de pequeña magnitud (figura 1).

El valle del Jequetepeque comprende una red de ciudades pequeñas y centros poblados, donde encontramos dos capitales de provincia: Chepén (44237 habitantes) y San Pedro de Lloc (13622 habitantes), en un territorio donde las principales actividades son agrícolas, industriales referida a la cementera Pacasmayo-y agroindustriales — referida a los molinos de arroz próximos a la vía Panamericana 
5 Esta red comprende también centros poblados ubicados en el río Marañón, en zona de explotación minera reciente. tersitarias 43-Especial

Figura 1. Región La Libertad y ubicación de las capitales de provincia de Chepén, San Pedro de Lloc, Otuzco y Huamachuco

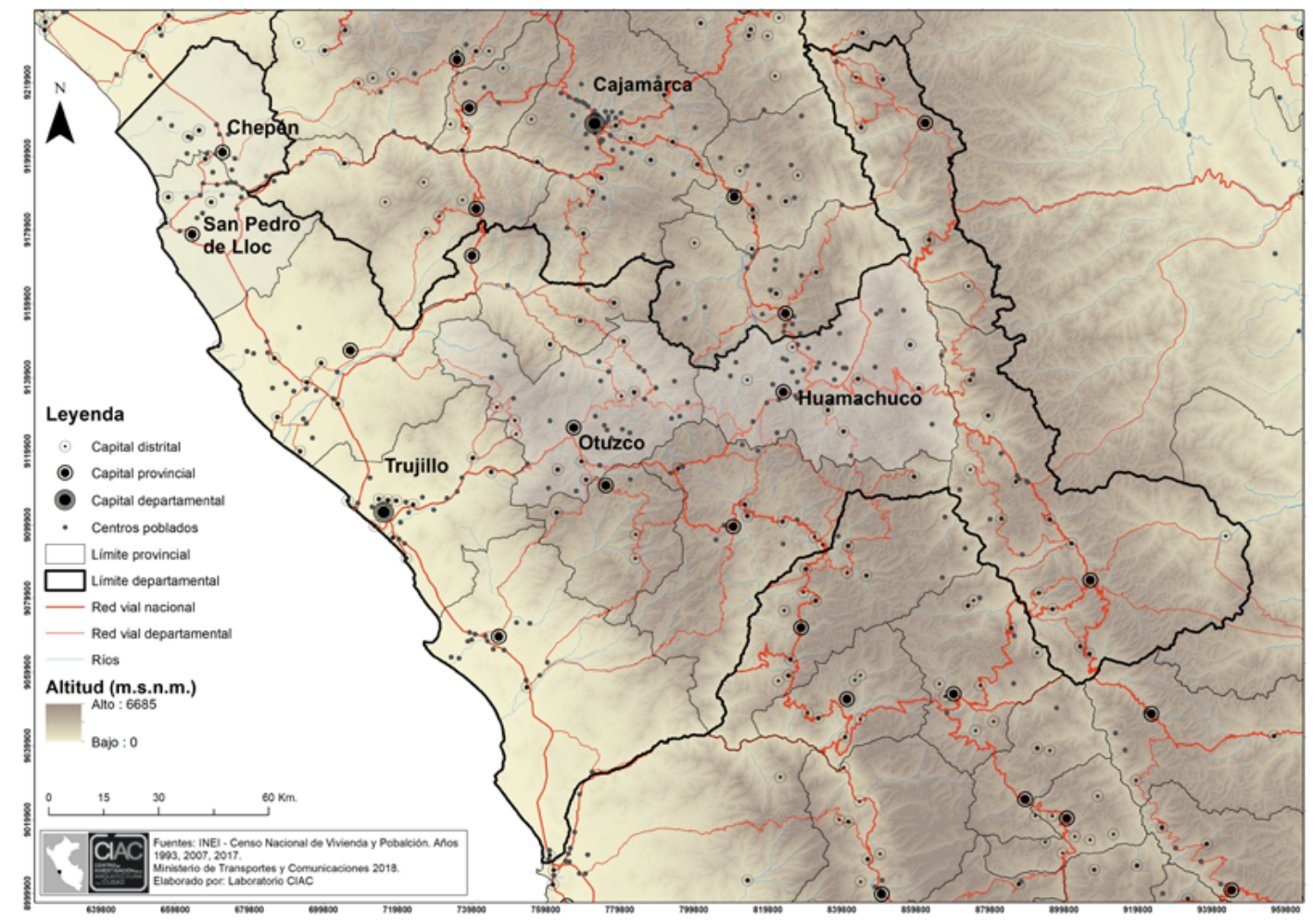

Fuente: Vilela et al. (2016).

Norte y a empresas de grandes capitales recientemente localizadas en el valle-.

Los centros poblados pertenecientes a la red están conectados vialmente, pero los servicios de transporte colectivo no cubren traslados a las localidades más pequeñas. En cambio, es frecuente la oferta de transporte a Trujillo y Chiclayo, las grandes ciudades del norte del país. Asimismo, será necesario prestar atención al proceso de habilitación de la denominada autopista El Sol — dos carriles de ida y dos de vuelta-, que unirá a las grandes ciudades en cerca de la mitad del tiempo actualmente requerido, cuyo trazo por el medio del valle no ha sido aún definido, por las expropiaciones que aún están pendientes. Este proyecto beneficiará la conectividad a gran escala, pero deja muchas interrogantes sobre sus efectos en las redes urbanas de escala local. 
El segundo caso es la red que comprende la capital provincial de Huamachuco (40000 habitantes) y los centros poblados ubicados en los pequeños valles que forman los ríos Grande, Toro y Bado. ${ }^{5}$ Esta red se organiza a partir de un solo centro, la capital de la provincia, que concentra tanto la actividad comercial y los servicios especializados, como los servicios relacionados con la minería en la región de pequeña, mediana y gran escala. La minería a gran escala inició sus operaciones en los años 2000 y eligió como centro de abastecimiento y de servicios a Huamachuco, generando un crecimiento urbano singular en su historia, pues hasta entonces los principales servicios se articulaban con la actividad agropecuaria y la minería de pequeña escala. La carretera de Huamachuco a Trujillo, gracias a la inversión pública, se ha mejorado notablemente desde el 2014, permitiendo que la distancia temporal se reduzca de 8 a 4 horas. ${ }^{6}$

La tercera red observada incluye la ciudad de Otuzco, capital provincial y centro de abastecimiento para los centros poblados del valle de los ríos Pollo y Huangamarca. En este territorio, las actividades predominantes son la agrícola y la pecuaria, y en menor medida la minera. Hasta principios del siglo XX, Otuzco desempeñó el papel de tambo o pascana para los viajeros que cubrían el trayecto entre Trujillo y Huamachuco. Esta ha cumplido históricamente un rol de enlace entre ciudades de mayor importancia regional.

\section{Densidad territorial: desigual concentración de servicios y oportunidades}

Durante las dos últimas décadas, el crecimiento demográfico ha sido dispar entre las ciudades estudiadas. En Huamachuco se observa un aumento de población constante, así como una expansión de su continuo urbano (figura 2, tabla 1). En Otuzco o San Pedro de Lloc, en cambio, el crecimiento poblacional se ha estancado, aunque existe un aumento de la superficie urbana en ambas localidades. Chepén se halla en una situación intermedia, con menor crecimiento poblacional, pero con un significativo incremento de su área urbana. Por otra parte, se registran casos como Pacanguilla o Ciudad de Dios-Pacatnamú en el valle del Jequetepeque, que sin ser capitales ni distrital ni provincial, han crecido demográficamente a una tasa elevada. Pacanguilla lo ha hecho por estar próxima a una de las principales plantas agroindustriales del país, de reciente habilitación, mientras que Ciudad de Dios-Pacatnamú debe su crecimiento a estar situada en el cruce de dos importantes carreteras nacionales, cuyo tráfico se ha incrementado luego del desarrollo de actividades mineras de escala global en Cajamarca, que usan intensivamente esas vías (figura 3 , tabla 2 ). En este caso, la lógica de ocupación es de baja dispersión, con solo 284 centros poblados (CCPP) que reúnen menos de 5000 habitantes (tabla 3).
${ }^{6}$ Inclusive, a principios del siglo $X X$, ese trayecto demandaba dos dias de camino, diferenciando 'la ruta agricola' (Huamachuco - Cajabamba - Usquil - Otuzco - Trujillo), de la actual, que es denominada por la población como 'la ruta minera' (Huamachuco Quirubamba - desvio de Otuzco-Trujillo).

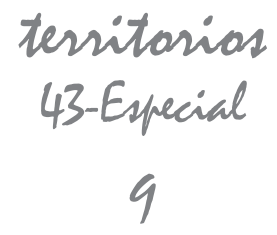


En Otuzco y Huamachuco, sus capitales de provincia reúnen alrededor de la quinta parte de la población total. No cuentan en sus entidades territoriales con otras ciudades de igual envergadura, pero sí con un enorme número de CCPP con menos de 500 habitantes que representan el $46.82 \%$ y $41.41 \%$, respectivamente. En otras palabras, en ambos casos se observa una lógica de ocupación numerosa y dispersa vinculada a una sola centralidad (tabla 3).

Figura 2. Crecimiento de superficie urbana y poblacional en las capitales de provincia de Otuzco y Huamachuco, 1993, 2007 y 2017 (años censales)
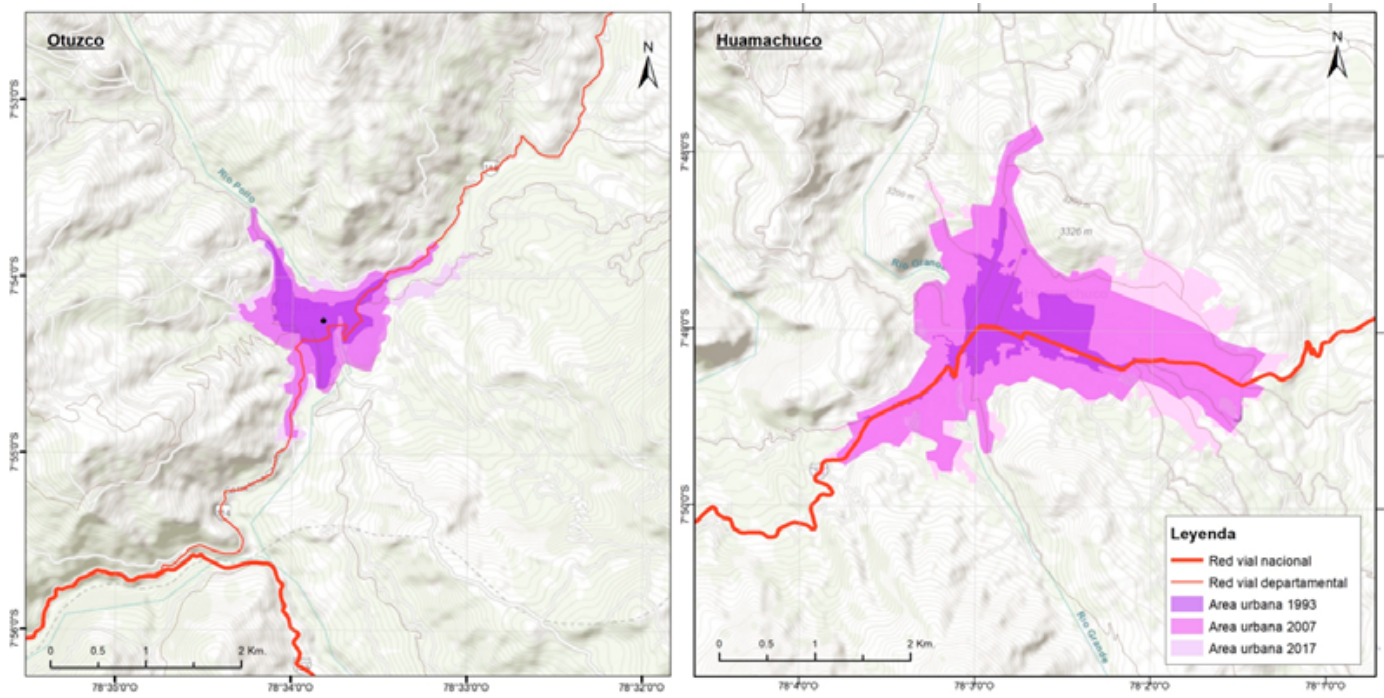

Fuente: Vilela et al. (2016).

Tabla 1. Crecimiento de superficie urbana y poblacional en las capitales de provincia de Otuzco y Huamachuco, 1993, 2007 y 2017 (años censales)

\begin{tabular}{|l|c|c|c|c|c|c|c|c|c|c|}
\hline \multirow{2}{*}{ Poblados } & \multicolumn{3}{|c|}{ Superficie por año (Has) } & \multicolumn{2}{|c|}{$\begin{array}{c}\text { Variación de } \\
\text { superficie (\%) }\end{array}$} & \multicolumn{4}{c|}{ Población } & \multicolumn{2}{c|}{$\begin{array}{c}\text { Tasa de } \\
\text { crecimiento (\%) }\end{array}$} \\
\cline { 2 - 12 } & 1993 & 2007 & $\mathbf{2 0 1 7}$ & $\begin{array}{c}(+) \\
\mathbf{9 3 - 0 7}\end{array}$ & $\begin{array}{c}(+) \\
\mathbf{0 7 - 1 7}\end{array}$ & $\mathbf{1 9 9 3}$ & $\mathbf{2 0 0 7}$ & $\mathbf{2 0 1 7}$ & $\begin{array}{c}\text { Periodo } \\
\mathbf{9 3 - 0 7}\end{array}$ & $\begin{array}{c}\text { Periodo } \\
\mathbf{0 7 - 1 7}\end{array}$ \\
\hline Otuzco & 55.30 & 140.67 & 155.47 & 154.38 & 10.52 & 8237 & 11489 & 12396 & 2.41 & 0.76 \\
\hline Huamachuco & 114.05 & 527.97 & 608.06 & 362.93 & 15.17 & 17693 & 28330 & 41613 & 3.42 & 3.92 \\
\hline
\end{tabular}

Fuente: Vilela et al. (2016). 
Figura 3. Crecimiento poblacional y del área urbana en las principales ciudades de la red del valle Jequetepeque, 1993, 2007 y 2017 (años censales)
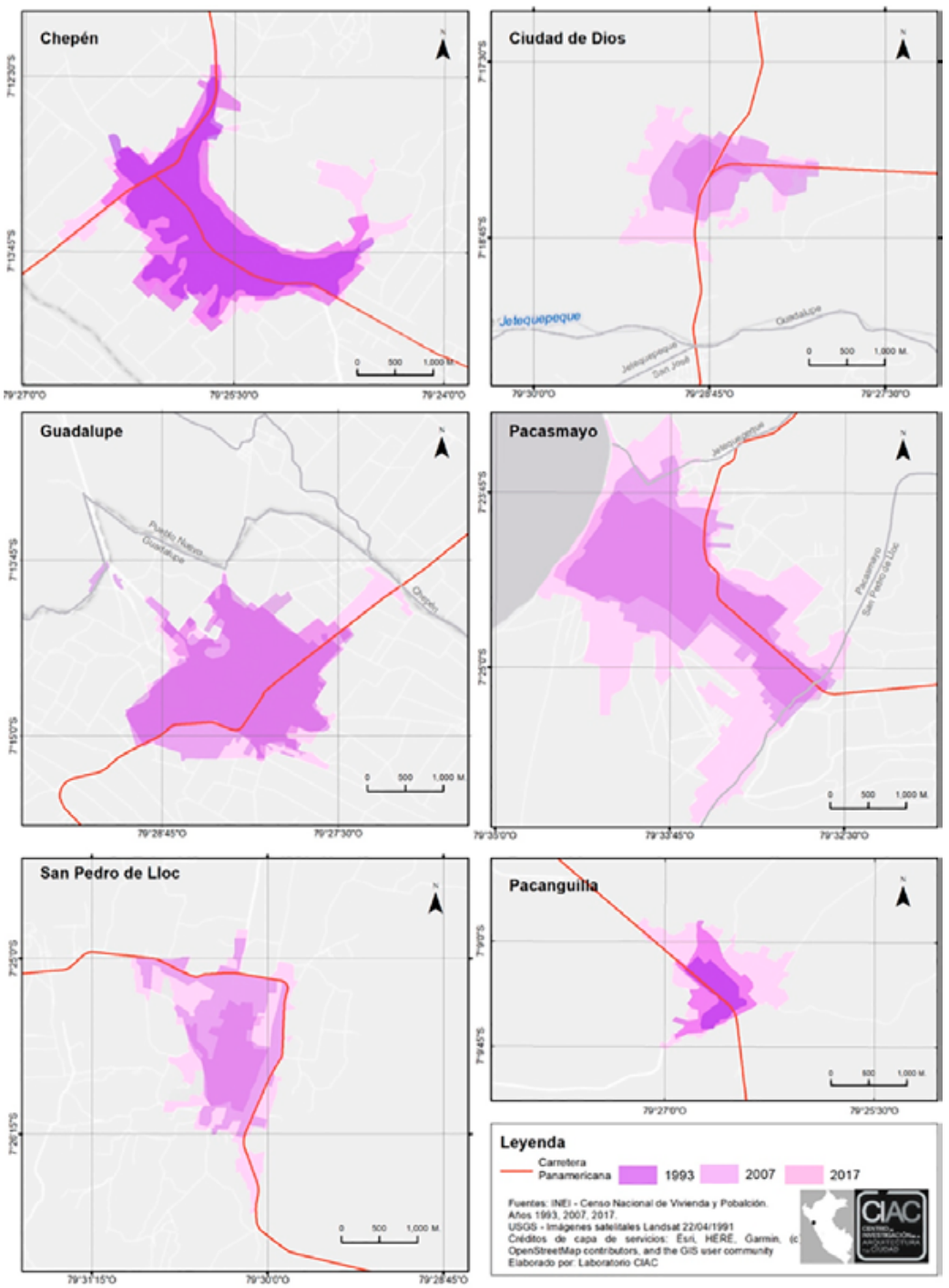

Fuente: Vilela et al. (2016). 
Tabla 2. Crecimiento de superficie urbana y poblacional en las principales ciudades de la red del valle Jequetepeque, 1993, 2007 y 2017 (años censales)

\begin{tabular}{|c|c|c|c|c|c|c|c|c|}
\hline \multirow{2}{*}{ Cuidades } & \multicolumn{3}{|c|}{ Superficie por año (Has) } & \multicolumn{2}{|c|}{$\begin{array}{l}\text { Variación de } \\
\text { superficie (\%) }\end{array}$} & \multicolumn{3}{|c|}{ Población } \\
\hline & 1993 & 2007 & 2017 & (+) 93-07 & (+) $07-17$ & 1993 & 2007 & 2017 \\
\hline Guadalupe & 323.21 & 379.55 & 459.03 & 14.84 & 17.31 & 7,103 & 20,605 & 21,857 \\
\hline Pacasmayo & 336.34 & 434.25 & 835.04 & 22.55 & 48.00 & 20,590 & 26,105 & 28,929 \\
\hline Chepén & 299.68 & 445.51 & 484.65 & 48.66 & 8.79 & 32,348 & 36,770 & 44,237 \\
\hline Ciudad de Dios & 36.84 & 144.48 & 229.96 & 74.50 & 37.37 & 1,928 & 6,678 & 8,696 \\
\hline San Pedro de Lloc & 80.87 & 208.17 & 321.70 & 61.15 & 35.29 & 8,715 & 12,171 & 13,622 \\
\hline Pacanguilla & 27.86 & 78.54 & 155.02 & 64.53 & 49.33 & 2,756 & 6,334 & 8,418 \\
\hline
\end{tabular}

Fuente: Vilela et al. (2016).

Tabla 3. Concentración poblacional y número de CCPP en los casos estudiados

\begin{tabular}{|l|c|c|c|c|c|c|}
\hline & \multirow{2}{*}{ Valle del Jequetepeque } & \multicolumn{2}{|c|}{ Otuzco } & \multicolumn{2}{c|}{ Huamachuco } \\
\cline { 2 - 7 } & 2007 & 2017 & 2007 & 2017 & 2007 & 2017 \\
\hline N $^{\circ}$ de cCPP hasta 500 habts. & 236 & 244 & 331 & 347 & 672 & 661 \\
\hline Población & 24307 & 20250 & 36668 & 31934 & 83904 & 78874 \\
\hline Población en porcentaje & 13.57 & 10.33 & 50.91 & 46.82 & 49.23 & 41.41 \\
\hline No de cCPP 501-5000 habts. & 37 & 40 & 20 & 18 & 42 & 36 \\
\hline Población & 46118 & 50013 & 23870 & 23873 & 58189 & 69992 \\
\hline Población en porcentaje & 25.75 & 25.51 & 33.14 & 35.00 & 34.14 & 36.75 \\
\hline No de cCPP 5000 o más habts. & 6 & 6 & 1 & 1 & 1 & 1 \\
\hline Población & 108663 & 125759 & 11489 & 12396 & 28330 & 41613 \\
\hline Población en porcentaje & 60.68 & 64.16 & 15.95 & 18.18 & 16.62 & 21.85 \\
\hline No de cCPP totales & 279 & 290 & 352 & 366 & 715 & 698 \\
\hline Población Total & 179088 & 196022 & 72027 & 68203 & 170423 & 190479 \\
\hline Población en porcentaje & 100 & 100 & 100 & 100 & 100 & 100 \\
\hline
\end{tabular}

Fuente: Vilela et al. (2016). 
La red centralizada de Huamachuco debe gestionar un territorio mucho mayor en extensión, es decir, que puede tener una unidad territorial de mayor amplitud. Por otro lado, la red de Otuzco, si bien es centralizada, es en parte dependiente de Trujillo, por su proximidad espaciotemporal con la capital de la región. Esto le demanda un doble rol, ${ }^{7}$ por una parte, es satélite de la ciudad de Trujillo y por otra, debe atender las demandas de su unidad territorial que no tienen conexión directa con la capital regional. En el caso del Valle del Jequetepeque, se conforma una red reticular, que se concentra en las ciudades mayores, que es poco dispersa y va consolidando una unidad territorial de menor extensión que en los otros casos.
Esto se puede corroborar con la localización de los servicios de salud y educación (figura 4), los cuales se encuentran mejor distribuidos espacialmente en el Valle del Jequetepeque, donde la alta conectividad - vías y servicios de transporte- facilita la accesibilidad de sus habitantes. La situación es diferente en Otuzco y Huamachuco, donde los servicios de educación y salud se encuentran concentrados en las capitales distritales y fundamentalmente en las capitales provinciales.

Cabe resaltar que todas las unidades territoriales cuentan con servicios de jerarquía semejante. Por ejemplo, todas cuentan con un Centro de Educación Superior Tecnológico. No obstante, la mayoría de jóvenes prefiere estudiar en

Figura 4. Unidad territorial definida por las relaciones de localización de los servicios de educación y salud en sus CCPP

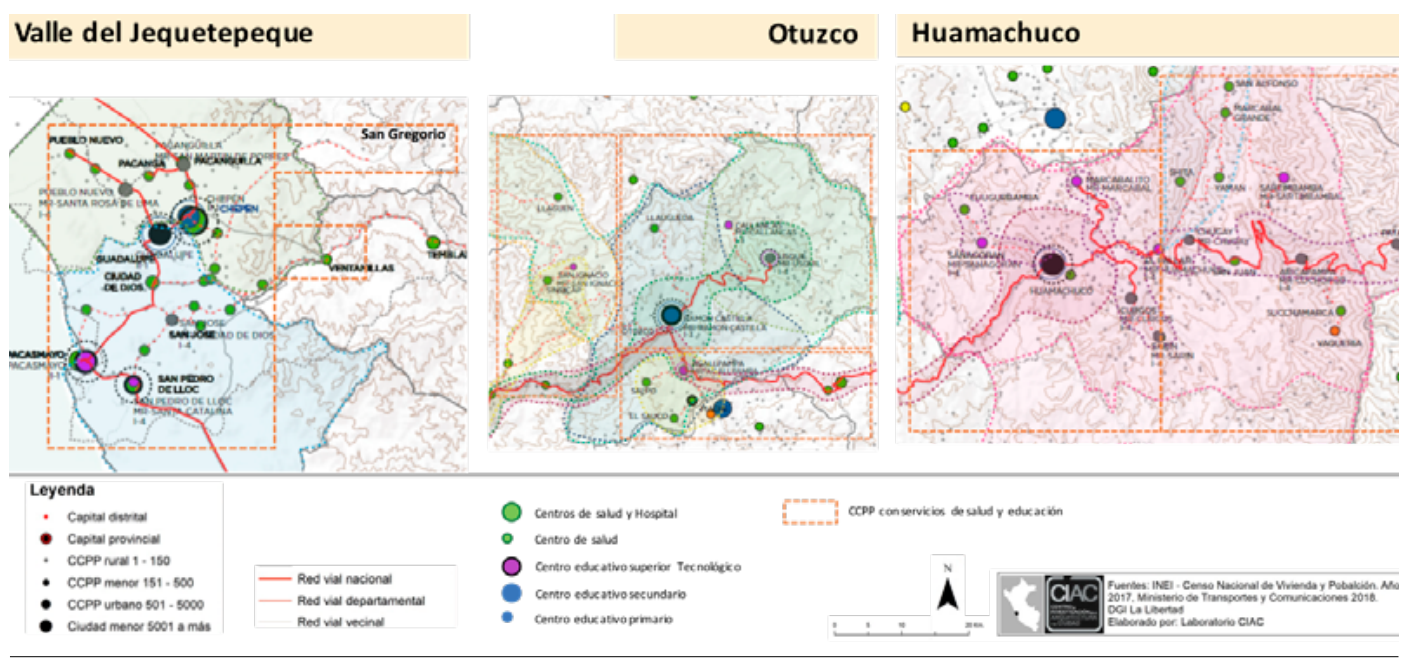

Fuente: Vilela et al. (2016). territarias 43-Especial
${ }^{7}$ Esta información fue obtenida de los testimonios de autoridades y organizaciones sociales expresados en las mesas de trabajo organizadas. 
Trujillo o Chiclayo (ambas capitales de región), atendiendo que la distancia temporal para los casos de Chepen y Otuzco es de dos horas aproximadamente. En el caso de Huamachuco en cambio, donde la distancia temporal a las grandes ciudades es superior a las cuatro horas, los jóvenes elijen permanecer en el centro de estudio superior de su localidad.

Las tendencias de concentración poblacional guardan relación con los servicios públicos ofrecidos en educación y salud tanto en infraestructura, como en la calidad del servicio (figura 5), que corresponde con el índice de desarrollo humano por distritos en la región (figura 6).

Por otra parte, los registros de cobertura vegetal y denuncios mineros (figura 7) indican correspondencia entre las inversiones viales y de comunicaciones de mayor envergadura y la minería, que se evidencian en la reducción de la contracción espaciotemporal. La superposición de esta información en planos pone en evidencia mayores desigualdades por contracción espaciotemporal según la cercanía o distancia a los mayores centros urbanos de la red.

En la figura 7 se observa una mayor concentración de denuncios mineros en la zona de Huamachuco; la extensión de cobertura vegetal se localiza en los valles de la costa, orientados a una agricultura más intensiva, mientras que las áreas de cobertura vegetal en la zona andina son fragmentadas y muchas veces superpuestas a los denuncios mineros. Esta situación se ve reflejada en la orientación de las inversiones públicas y privadas: en Huamachuco hacia la minería y en los valles de la costa hacia la industria de agroexportación.

Figura 5. Desnutrición crónica en niños menores de 5 años y logros de aprendizaje en matemáticas, región La Libertad, 2014

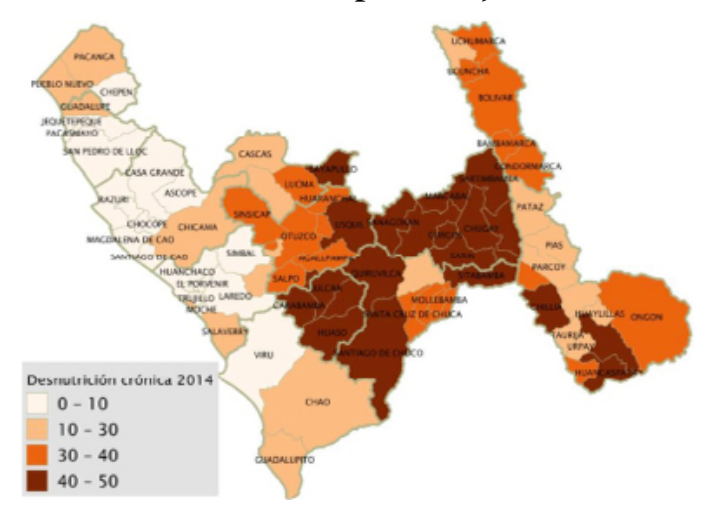

Tasa de desnutrición crónica en niños menores de 5 años. OMS.

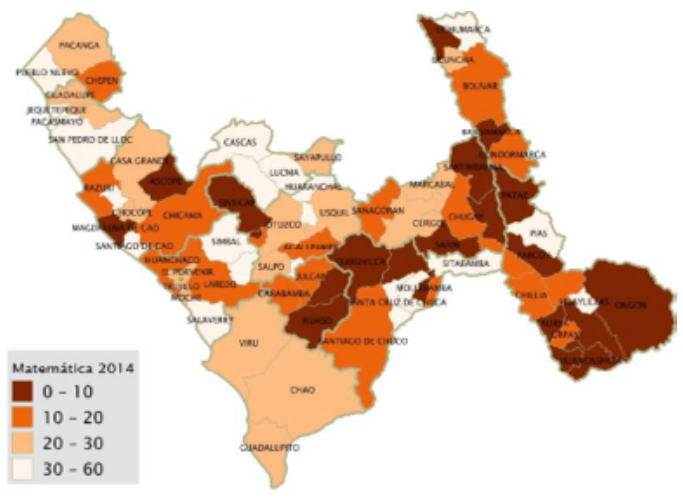

Logros de aprendizaje en matemáticas, 2014 
Figura 6. Índice de desarrollo humano por distrito en región La Libertad, 2014

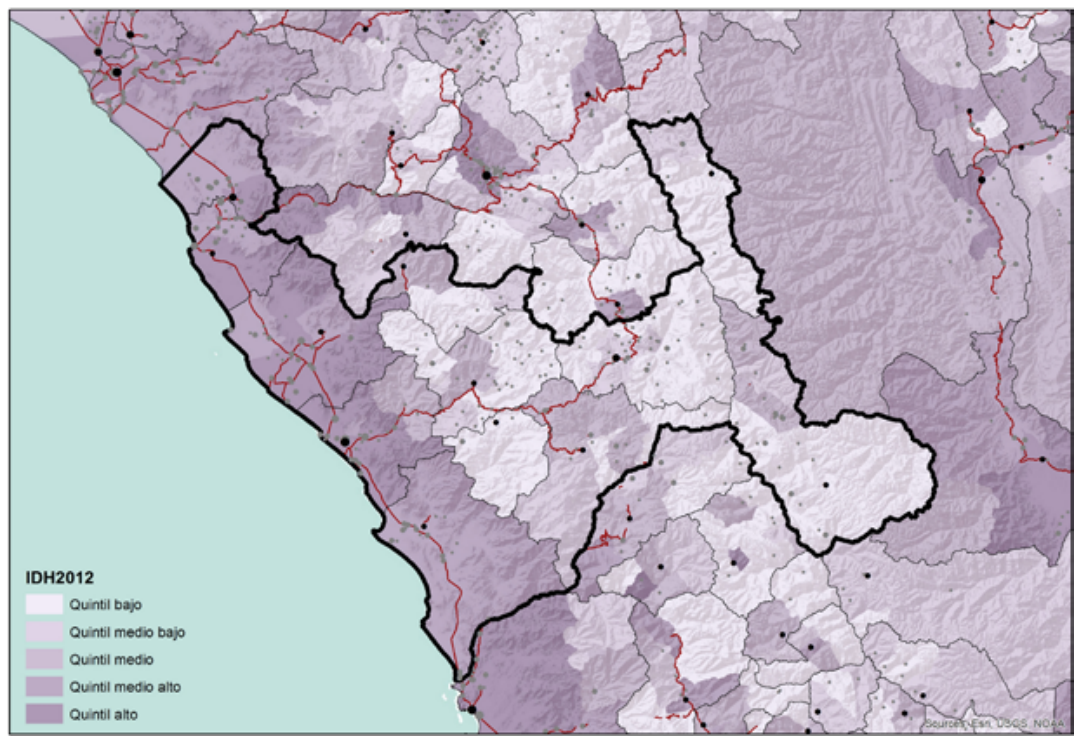

Fuente: Vilela et al. (2016).

Figura 7. Recursos de suelo por cobertura vegetal y zonas de denuncios mineros: La Libertad, 2017

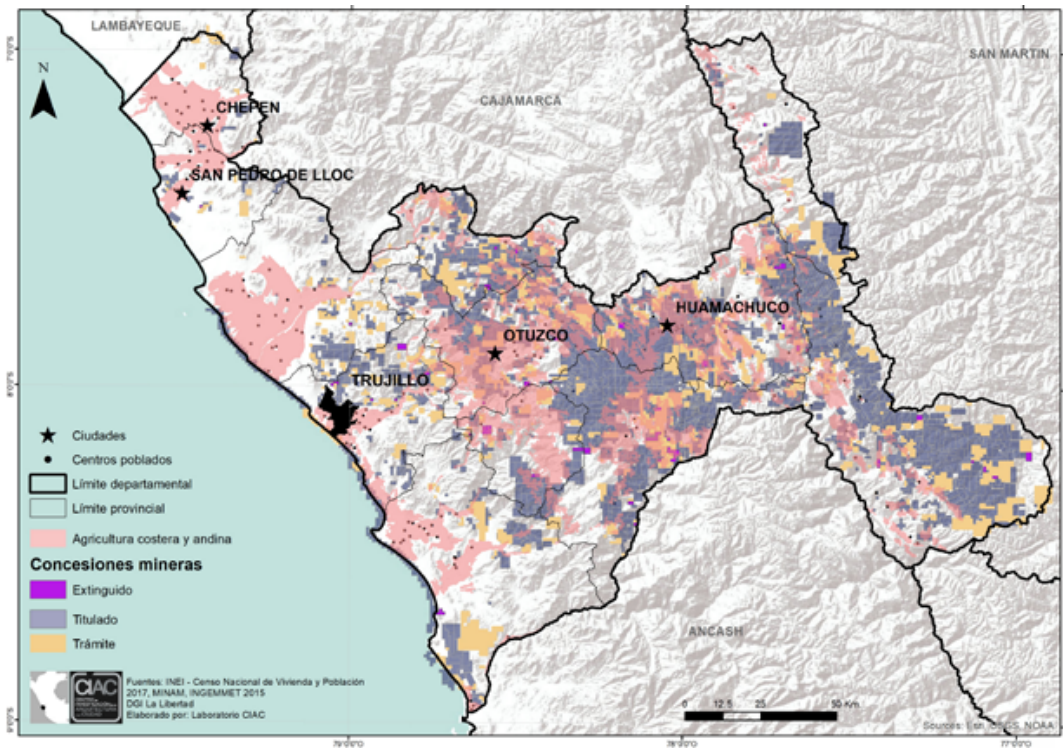

territorios

43-Especial

Fuente: Vilela et al. (2016). 
Los funcionarios y autoridades de los gobiernos locales no logran atender de manera eficiente la complejidad de su unidad territorial en sus dinámicas de intermediación - sean estas de ámbito distrital o provincial-. En este contexto, es relevante el esfuerzo de la gestión local de Huamachuco, que creó su Centro Provincial de Planeamiento Territorial (CEPPLAN) para mejorar sus competencias en el trabajo con los centros poblados de su extensa red territorial, que es donde se registran mayores desigualdades. Esta situación se agudizó a raíz del incremento de la actividad minera, que presionó por la articulación de los servicios que requería por encima de otras actividades.

La pendiente (figura 8) es una variable determinante para la accesibilidad en un país andino. Además, el tipo del suelo condiciona la contracción espacio temporal entre los CCPP de una unidad territorial.

\section{tersitorias 43-Especial}

\section{Figura 8. Las pendientes del territorio en los tres casos}
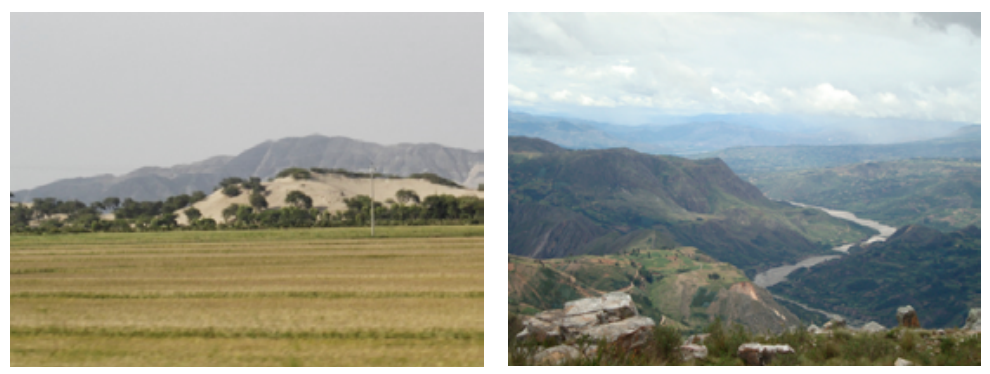

Zona Agrícola: cultivo de arroz del Valle Jequetpeque, 2015

Fuente: Vilela et al. (2016).
Los centros urbanos pequeños establecen redes de movilidad funcional en el caso de que consoliden una unidad territorial; estas muchas veces superan los límites provinciales o regionales, generando lo que Salazar et al. (2017) enuncian como un desfase escalar. Esto no solo se evidencia en el ámbito espacial, sino también en la gestión territorial, ya que la perspectiva del gobierno local difiere de la del gobierno regional. Esta situación ocurre en la relación de Chepén con los CCPP de la zona de San Gregorio que si bien no pertenecen a la misma provincia ni región, sí se relacionan por comercio y servicios, a pesar de que la contracción espaciotemporal demande viajes de 2 horas y media, pues la relación de estos CCPP con las grandes ciudades de su región supone distancias espaciotemporales aún mayores (figura 9).

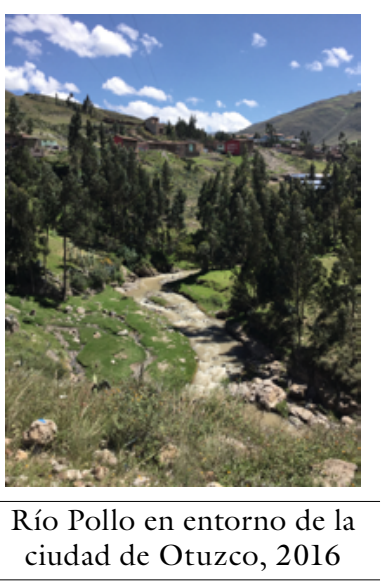
ciudad de Huamachuco, 2017

ciudad de Otuzco, 2016


Figura 9. Contracción espaciotemporal a partir de las capitales de distritos en la región La Libertad, 2017

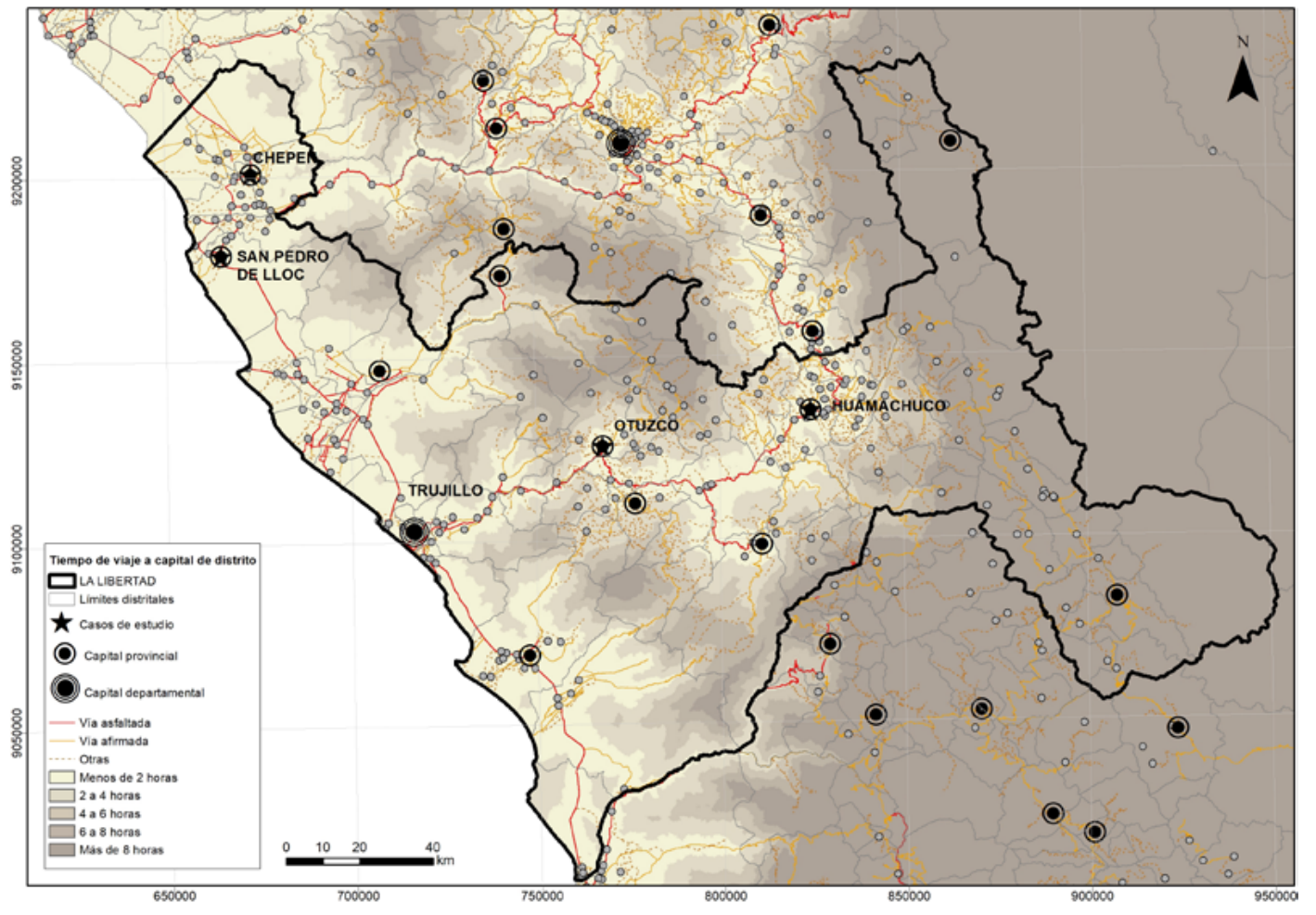

Fuente: Vilela et al. (2016).

En el caso de Otuzco, la fragmentación de la unidad territorial se debe a su proximidad con Trujillo, la capital regional. Las nuevas vías y la importante oferta de servicios de transporte hacen más fácil a varios CCPP llegar a Trujillo que a la capital de la provincia a la que pertenecen jurisdiccionalmente. Esta situación se evidenció con el asfaltado de la vía Trujillo-Huamachuco en 2012. Como consecuencia de esta vía, pensada para facilitar los accesos carreteros de los sitios mineros, Otuzco perdió su influencia sobre la parte sur de su antigua unidad territorial.

De otro lado, es notable observar el incremento de las desigualdades entre la localidad de Curgos y su entorno próximo, dentro de la provincia de Sánchez Carrión. Este centro poblado, capital de distrito, se ubica a tan solo 35 minutos en transporte público de la capital de la provincia, pero tiene los índices más bajos en rendimiento escolar, los más altos en desnutrición infantil y el Índice de Desarrollo Humano tersitorios 43-Especial 
${ }^{8}$ Los niños procedentes de CCPP dispersos acuden los lunes al colegio en la ciudad de Huamachuco y se bospedan hasta el viernes con familiares, para ese dia, finalizadas las clases, retornar a sus hogares.

tersitarias 43-Especial más bajo del país. ¿Qué ha ocurrido en este caso? Se trata de una localidad cuya economía es predominantemente agropecuaria, pero que quedó al margen de las recientes redes viales, lo que afectó su inserción en la actividad económica de Huamachuco, dominada por la minería.

En lo referido a la conectividad, la totalidad de la población en la unidad territorial del Valle Jequetepeque se encuentra interconectada; el $85 \%$ cubre las hora y el resto de 2 horas. En la unidad territorial referida a Otuzco, en cambio, el $55 \%$ de la población se encuentra a una distancia menor de dos horas, el $35 \%$ de 3 horas y el resto a más de 4 horas. En la unidad territorial de Huamachuco, distancias con una fracción menor a 1

el $32 \%$ debe cubrir una distancia de 2 horas a la ciudad de Huamachuco, el $47 \%$ de 3 horas y el $21 \%$ de más de 4 horas. Debido al largo tiempo que suponen los desplazamientos, estos ocurren, por lo general, de manera hebdomadaria, como es el caso de la actividad escolar ${ }^{8}$ o la comercial concentrada en los mercados y ferias, que no se ha considerado en esta oportunidad (figura 10).

\section{Las tipologías de redes territoriales y las estrategias de desarrollo}

La red territorial en el valle del Jequetepeque adopta una tipología reticular, con dos capitales de provincia dentro de ella —San Pedro de Lloc y Chepén-y

Figura 10. Unidad territorial caracterizada por la contracción espaciotemporal en las relaciones de CCPP con capitales provinciales

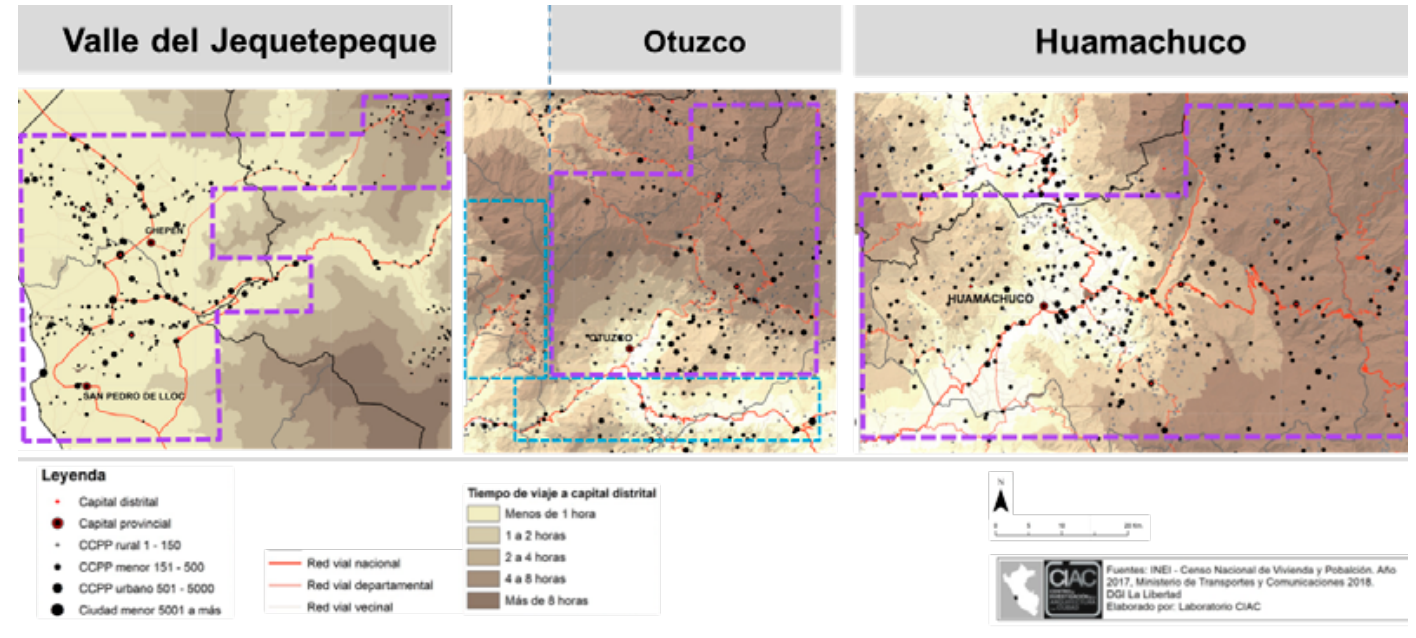

Fuente: Vilela et al. (2016). 
otras cuatro ciudades con más de 8000 habitantes, cubriendo un espacio aproximado de $1700 \mathrm{~km}^{2}$, incluyendo 290 CCPP de diferente tamaño, con un total de 196022 habitantes (INEI, 2018). Esta red se soporta económicamente en el cultivo de arroz y sus encadenamientos productivos - molinos y transporte de carga, entre otros- y recientemente en la agroindustria suprarregional y nacional - sistema de alta producción-, que concentra mano de obra local.

Esta red de ciudades se ha ido consolidando con el tiempo. Durante la época colonial se localizaron en el valle una diversidad de asentamientos, como la reducción de indios en Chepén, el monasterio de Guadalupe, el puerto en Pacasmayo, y la "ciudad de españoles" en San Pedro de Lloc, aprovechando la extensión del valle y las preexistencias prehispánicas. Hacia finales del siglo XIX, con la habilitación de la red ferroviaria, se fortaleció la articulación de las haciendas con los asentamientos y la extracción minera con el puerto. Para 1950, la construcción de la carretera Panamericana norte supuso un cambio en la articulación del territorio, en que se privilegió la conexión de las ciudades pequeñas existentes. Esta red se ha venido consolidando por la capacidad de los CCPP de adaptarse a lo largo del tiempo, que ahora deberá enfrentarse al riesgo que supone el futuro trazo de la autopista El Sol.

La red territorial en Huamachuco adopta una tipología centralizada, que comprende un espacio de alrededor de $2700 \mathrm{~km}^{2}$ con la capital provincial y 698 CCPP para albergar 190479 habitantes, de los cuales cerca de un tercio habita en la ciudad de Huamachuco. Esta enorme brecha demográfica entre la capital y los demás CCPP evidencia una dualidad que se sustenta en la economía agropecuaria y minera. La actividad minera a gran y mediana escala ha propiciado el crecimiento poblacional de la capital que se combina con actividades agropecuarias de comercialización y subsistencia (Gonzales, 2017).

Esta dualidad minera y agropecuaria ha venido modificando la lógica de ocupación desde mediados del siglo XX. Anteriormente predominaba la actividad agropecuaria, lo que se expresaba en el trazo de la vía Huamachuco-Otuzco-Trujillo, que pasaba al norte del trazo actual a fin de conectar diversos CCPP agrícolas. Sin embargo, con el desarrollo de la gran minería, la vía priorizada pasa por el sur uniendo CCPP mineros como Quiruvilca, lo que ha relegado a los antiguos CCPP de actividad agrícola y pecuaria. ${ }^{9}$

La red territorial en Otuzco también tiene una tipología centralizada, aunque a doble escala; comprende un espacio de cerca de $1400 \mathrm{~km}^{2}$, agrupa 366 CCPP y se compone de 68203 habitantes. El acceso a Otuzco es sencillo a partir de un corto desvío que toma menos de 15 minutos desde la carretera Trujillo-Huamachuco. Esta vía, habilitada en 2014, ha supuesto la pérdida de su jerarquía como capital
${ }^{9}$ En las mesas de trabajo, los adultos mayores todavía identifican la antigua carretera como la vía agricola, diferenciándola de la vía minera. 
provincial, que la ha convertido parcialmente en un satélite de la metrópoli de Trujillo, ya que hoy en día la distancia temporal es de 1.45 horas, con una elevada oferta de transporte colectivo. La reducción de su antigua unidad territorial ha permitido que Usquil — capital de distrito, localizado en la antigua vía agrícola hacia Huamachuco- emerja como pívot, articulando la producción agrícola y pecuaria de gran parte de esta unidad territorial. Esto se explica porque su localización es más céntrica para los diferentes CCPP menores, dependientes de la actividad agrícola y pecuaria.

Como se ha podido comprobar, existe una reorganización espacial de las tipologías territoriales locales influenciada por las grandes inversiones de escala nacional e inclusive global en las unidades territoriales observadas, cuya localización tendrá impacto en la tipología de la red a diferentes escalas espaciales.

La tipología reticular de la red territorial tiende a la concentración espacial de sus CCPP constituyendo espacios territoriales más densos, donde la proximidad física o menor distancia es la condición que soporta el dinamismo de las relaciones cotidianas a escala temporal (figura 11). Este es el caso de las provincias de Pacasmayo y Chepén, donde la accesibilidad a la diversidad de servicios de la red permite a la población alcanzar mejores índices de desarrollo humano. Esta red se concentra como unidad territorial. Sin embargo, pese a su baja contracción espaciotemporal se ha constituido de forma reticular, con mayor densidad.

La tipología de centralidad única con dispersión de CCPP en su unidad territorial expresa una relación de desigualdad

Figura 11. Tipologías de redes territoriales locales

tersitarias 43-Especial

\section{Figura 11. Tipologias de redes territoriales locales}

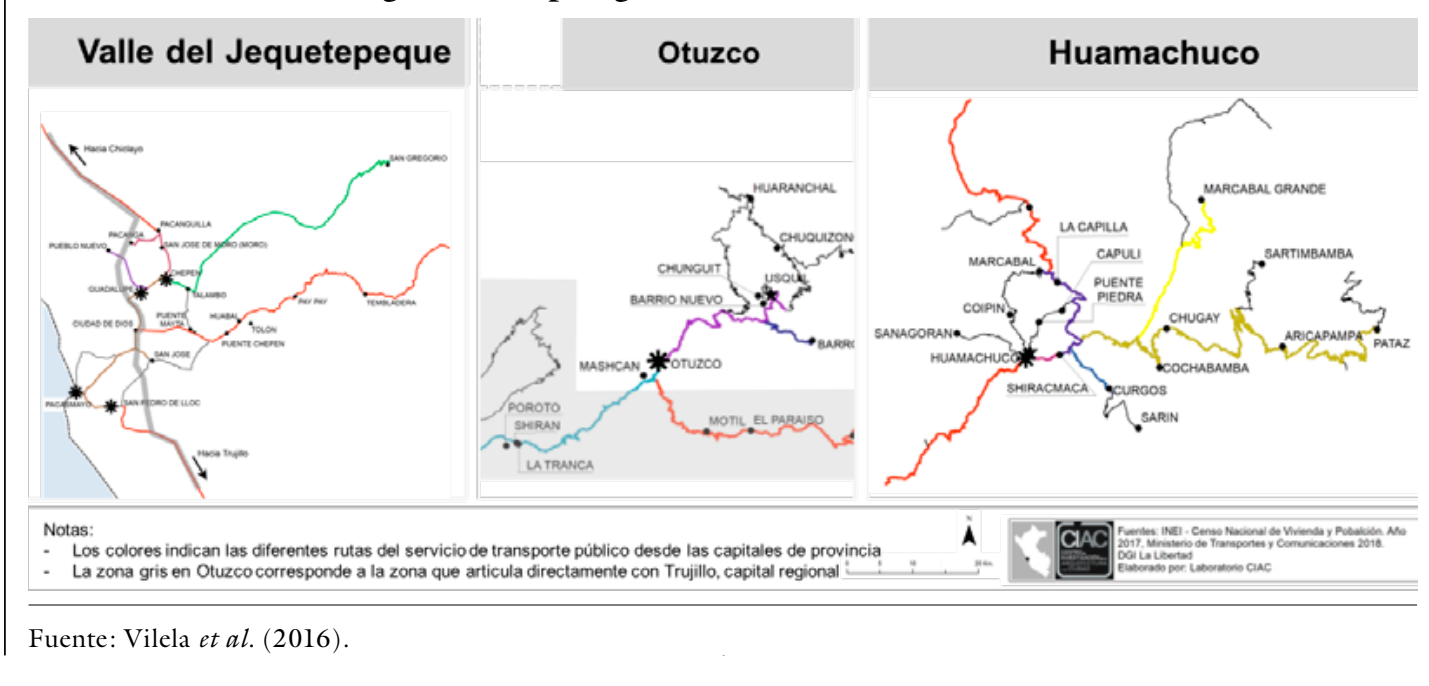


entre las oportunidades y equipamientos, evidenciada en la densidad poblacional y distribución de servicios, y agudizada por las condiciones geográficas de alta contracción espaciotemporal. Asimismo, expresa una relación temporal diferenciada en la conectividad que es la condición que sustenta las dinámicas cotidianas.

Este es el caso de las provincias de Otuzco y Sánchez Carrión-Huamachuco, ambas de baja densidad en su unidad territorial, donde se mantiene y va mejorando lentamente en los indicadores de calidad de los servicios de salud y educación. Cabe recordar que en el caso de Otuzco si bien es una tipología centralizada, esta se fragmenta por la proximidad a Trujillo. En el caso de Huamachuco se observa que si bien es centralizada, puede articular una gran superficie, pese a la alta contracción espaciotemporal de su extenso territorio.

Esta lectura tipológica invita a enfocar la promoción al desarrollo, a través de la calidad de los servicios públicos y su acceso local, considerando la contracción espaciotemporal y la extensión de su unidad territorial. La identificación de tipologías en unidades territoriales puede abarcar la organización de territorios más extensos, con diversidad de actividades económicas, reconsiderando un soporte físico-territorial altamente diverso, pero con la localización dispersa de recursos.

Un ordenamiento territorial sostenible y equilibrado en el uso más racional de sus recursos requiere de la construcción social de relaciones espaciales y valorar el papel que tienen las ciudades pequeñas en las unidades territoriales donde no existen grandes urbes, como los casos estudiados (figura 12).

\section{Conclusiones}

Las ciudades pequeñas aquí estudiadas articulan gran parte de la población, a través de redes de CCPP en sus unidades territoriales, gracias al rol de intermediación que juegan a escala local. Estas redes conforman tipologías espaciales que demuestran que las desigualdades no dependen solamente de la accesibilidad vial a determinados servicios, sino también de la localización de estos, sobre todo cuando nos situamos en territorios con gran cantidad de CCPP muy pequeños y dispersos en un geografía accidentada, donde las pendientes del terreno condicionan una mayor contracción espaciotemporal.

Podemos afirmar entonces que estas ciudades tienen una gran responsabilidad en sus unidades territoriales al cumplir el rol de intermediación por su capacidad de constituirse como espacios de intercambio y oferta de servicios especializados para su región.

Las tipologías de redes de ciudades constituyen pues una herramienta para el ordenamiento territorial sostenible desde un enfoque territorial. De acuerdo con ello, estas pueden contribuir a reducir los desequilibrios territoriales y evidenciar tersitarios 43-Especial 


\section{territarias 43-Especial}

Figura 12. Vistas de las ciudades capitales de provincia San Pedro de Lloc, Chepén, Otuzco y Huamachuco
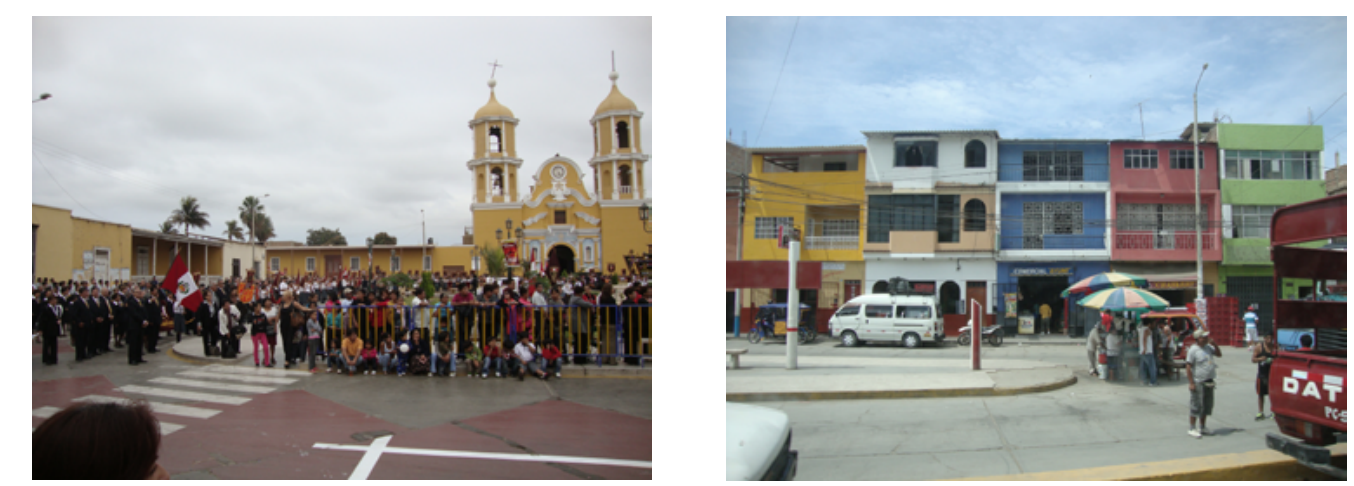

Plaza de Armas de San Pedro de Lloc, 2014

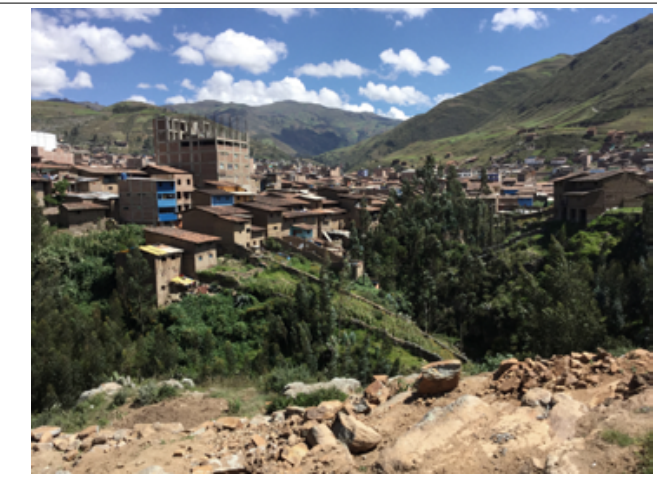

Vista de la ciudad de Otuzco, 2016
Calle principal de Chepén, 2018

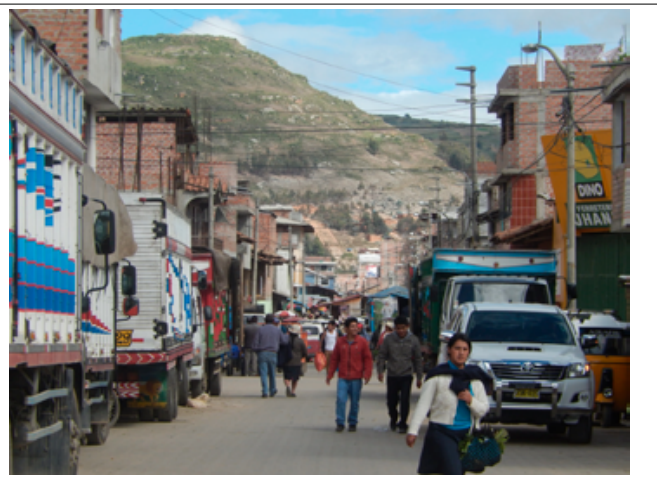

Huamachuco, vía principal al mercado, 2017

Fuente: Vilela et al. (2016).

las desigualdades en el país que pueden generar inversiones de escala nacional o global si imponen sus lógicas de encadenamientos sin una adecuada comprensión y relación con la unidad territorial en la que se insertan.

En países como el Perú, los planes de desarrollo de ciudades pequeñas y sus respectivos distritos tienden a ser desarrollados como unidades autónomas e independientes, dejando de lado la importancia de las articulaciones e interdependencias que establecen con otros CCPP de igual, mayor o menor jerarquía. Es necesario tejer identidades territoriales no tanto en los centros como unidades autónomas, sino con base en las redes territoriales de las cuales forman parte. 
Lo que ofrece el análisis tipológico es una lectura de cómo se tejen estas redes, sin calificar unas como mejores y otras como peores, sino que atiende a la densidad de ocupación y las contracciones espaciotemporales.

\section{Referencias}

Bellet, C., \& Llop J. (2004). Miradas a otros espacios urbanos: las ciudades intermedias. Scripta Nova, 8(165), 157-180. http://www.ub.edu/geocrit/ $\mathrm{sn} / \mathrm{sn}-165 . \mathrm{htm}$

Bernard, G. (2015). Ruptures urbaines: une pragmatique spatio-temporelle. Ethnographies du changement et de l'attachement. Parcours Anthropologiques, (10), 46-64. https://doi. org/10.4000/pa.422

Bielza de Ory, V. (2012). Organización y ordenamiento del territorio. Desarrollo y sostenibilidad. Experiencia europea para el Perú. Revista Geográfica, (152), 84-103. https://www.jstor.org/stable $/ 43558256$

Bretagnolle, A., Pumain, D., \& VacchianiMarcuzzo, C. (2010). The organisation of urban systems. En Pumain Lane \& West Van der Leeuw (Eds.), Complexity perspective in innovation and social change (pp. 197-220). Springer. https://doi.org/10.1007/978-14020-9663-1_7

Calderón, J., \& Vega Centeno, P. (2016). La cuestión urbana en Perú: balances y perspectivas para el siglo XXI. En P.
Metzger, J. Rebotier, J. Robert, P. Urquieta, \& P. Vega Centeno (Eds.), La cuestión urbana en la región andina. Miradas sobre la investigación y la formación (pp. 175-222). Centro de Publicaciones Pontificia Universidad Católica de Ecuador.

Carrión, F. (2013). Ciudades intermedias: entre una pirámide trunca y una red urbana en construcción. En José Canziani \& Alexander Schetjman (Eds.), Ciudades intermedias y desarrollo territorial (pp. 21-31). Fondo Editorial de la Pontificia Universidad Católica del Perú.

Castells, M. (1973). Imperialismo y urbanización en América Latina. Gustavo Gili.

CERPLAN-GRll Centro Regional de Planeamiento Estratégico (2016). Estudio prospectivo: Región La Libertad al 2030. Gobierno Regional La Libertad.

Demazière, C. (2017). Le traitement des petites et moyennes villes par les études urbaines. Espaces et sociétés, 1-2(168169), 17-32. https://doi.org/10.3917/ esp.168.0017

Enríquez, F. (Coord.). (2019). Territorialización de la política pública y gobernanza. Ediciones Abya-Yala, Gobiernos Autónomos Provinciales del Ecuador.

Gallicchio, E. (2010). El desarrollo local: ¿territorializar políticas o generar políticas territoriales? Reflexiones desde la práctica. Eutopia, (1), 11-23. https:// doi.org/10.17141/eutopia.1.2010.933 territarios 43-Especial 


\section{tersitarias} 43-Especial 24
Gonzales, A. (2017). Minería, formas de urbanización y transformación del espacio en Huamachuco, La Libertad, Perú. Bulletin de l'Institut d'Etudes Andines, 46(3), 509-527. https://doi. org/10.4000/bifea. 8968

Haesbert, R. (2013). Del mito de la desterritorialización a la multiterritorialidad. Cultura y Representaciones Sociales, 8(15), 9-42.

Hall, P., \& Pain, K. (2006). The polycentric metropolis: Learning from mega-city regions in Europe. Earthscan.

Instituto Nacional de Estadística e Informática (INEI). (2008). Resultados del Censo Nacional de Población y Vivienda 2007. https://www.inei.gob.pe/ media/MenuRecursivo/publicaciones_digitales/Est/Libl136/index. htm

Instituto Nacional de Estadística e Informática (INEI). (2018). Resultados del Censo Nacional de Población y Vivienda 2017. http://censos2017.inei.gob.pe/ redatam/

Llop, J., Iglesias, B., Vargas, R., \& Blanc, F. (2019). Las ciudades intermedias: concepto y dimensiones. Ciudades, (22), 23-43. https://doi.org/10.24197/ ciudades.22.2019.23-43

Magnaghi, A. (2011). El proyecto local, hacia una conciencia del lugar. Universitat Politecnica de Catalunya.

Máttar, J., \& Riffo, L. (2013). Territorial development in Latin America: A long term perspective. En Juan R. Cuadrado-Roura \& Patricio Aroca (Eds.),
Regional problems and policies in Latin America (pp. 43-68). Springer. https://doi.org/10.1007/978-3-64239674-8_3

Montoya, J., \& Duque, I. (2017). El subsistema de ciudades medias en Colombia y su integración al sistema urbano nacional. En Francisco Maturana, María Encarnação Beltraão Sposito, Carmen Bellet, Cristián Henríquez \& Federico Arenas (Eds.), Sistemas urbanos y ciudades medias en Iberoamérica (pp.110-143). Pontificia Universidad Católica de Chile.

Oxfam. (2014). Iguales. Acabemos con la desigualdad extrema. Oxfam.

Pulido, N. (2004). Globalización y surgimiento de ciudades "intermedias" en América Latina y en Venezuela. Revista Geográfica Venezolana, 45(1), 91-121.

Salazar, G., Irarrázaval, F., \& Fonck, M. (2017). Ciudades intermedias y gobiernos locales: desfases escalares en la Región de La Araucanía, Chile. EURE. Revista Latinoamericana de Estudios Urbano Regionales, 43(130), 161-184.

Schejtman, A. (2013) Desarrollo territorial rural y ciudades intermedias. En José Canziani \& Alexander Schejtman (Ed.), Ciudades intermedias y desarrollo territorial (pp. 33-58). Pontificia Universidad Católica del Perú.

Schneider, S., \& Peyré, I. (2006). Territorio y enfoque territorial: de las referencias cognitivas a los aportes aplicados a los análisis de los procesos sociales rurales. En Mabel Manzanal, Guillermo 
Neiman (Comps.), Desarrollo rural. Organizaciones, instituciones y territorio (pp. 71-102). Ciccus.

Schor, T., \& de Oliveira, J. (2011) Reflexões metodológicas sobre o estudo da rede urbana no Amazonas e perspectivas para a análise das cidades na Amazônia Brasileira. Acta Geográfica, Edição Especial “Cidades na Amazônia Brasileira", 15-30. http://dx.doi. org/10.5654/acta.v5ill.539

Vilela, M., M. (2009). Construcción de un modelo espacial de redes territoriales para ciudades intermedias. Redes de ciudades en el valle bajo del Jequetepeque. Universidad de Lieja.
Vilela, M. (2017) El diseño de escenarios exploratorios de ocupación urbana en la prospectiva territorial. Valle del Jequetepeque/Cupisnique 2007-2017. Espacio y Desarrollo, (30), 9-36. http:// revistas.pucp.edu.pe/index.php/espacioydesarrollo/article/view/19546

Vilela, M., Vega Centeno, P., Fernández de Córdova, G., Moschella, P., \& Bensús, V. (2016). Ciudades intermedias y estructura territorial frente a los desafios de la globalización. El caso de la Región La Libertad. Proyecto de Investigación (2016-2018), Centro de Investigación de la Arquitectura y la Ciudad (CIAC). Pontificia Universidad Católica del Perú (PUCP). 